\title{
Financial impact of COVID-19 on radiology practice in India
}

\section{Gauri Ahuja, Mitusha Verma, Deepak Patkar ${ }^{1}$}

Department of Imaging and Diagnosis, Nanavati Super Speciality Hospital, 'Department of Imaging, Nanavati Super Speciality Hospital, Mumbai, Maharashtra, India

Correspondence: Dr. Gauri Ahuja, 1701B Wing Sweet Home SVP Nagar, Versova, Andheri West Mumbai - 400053 , Maharashtra, India. E-mail: gaurane@gmail.com

\begin{abstract}
The COVID-19 pandemic will have serious financial effects on the healthcare sector business. There will be significant short-term and long-term effects of this on Radiology services throughout the country. Various social distancing measures undertaken by the government will bring larger economic hurdles with them. An attempt to achieve COVID-19 preparedness by hospitals has led to a significant decline in patient footfall and in turn imaging volumes. Despite relief measures provided by the government like providing a moratorium on EMls of all outstanding loans for a specified period and allocating funds toward reinforcing healthcare infrastructure, the effects of this pandemic will leave the radiology business in a crippled state, in the foreseeable future. Radiology practices have seen a significant impact on business to the extent of almost $60 \%-70 \%$ reduction in imaging volumes and this will be the case for the next few months to come. Administrators and radiologists should proactively take measures to device strategies and plans to tide over this crisis. Eventually, this pandemic will end, and life will have a "New Normal." Medical aid that is being deferred today will be sought out later. Alternate means of reporting like teleradiology and artificial intelligence should be strongly pursued and providing education regarding these to their staff and the younger generation of radiologists should be of prime concern.
\end{abstract}

Key words: Economic impact radiology; radiology in India; financial impact of COVID; COVID-19 impact; reduced revenue radiology

\section{Introduction}

The coronavirus disease (COVID-19) caused by SARS-CoV-2 began in Wuhan, China. The WHO declared it as a global pandemic on March $11^{\text {th }} 2020 .^{[1]}$ It is evolving rapidly, widely disrupting personal and professional life. The healthcare sector lies at the epicenter of this unprecedented global pandemic challenge.

Radiology services aid in the surveillance and management of COVID-19 patients. $^{[2]}$ Difficult times lie ahead for our entire healthcare system including radiology services as the financial impact of the COVID-19 pandemic will have both short-term and long-term effects.

\begin{tabular}{|l|l|}
\hline \multicolumn{2}{|c|}{ Access this article online } \\
\hline Quick Response Code: & \\
\cline { 1 - 2 } & Website: \\
& www.ijri.org \\
\cline { 2 - 3 } & DOI: \\
&
\end{tabular}

It is essential to flatten the curve to make sure that health services are not overwhelmed by the number of coronavirus cases. On the evening of March $24^{\text {th }}$, Prime Minister Narendra Modi declared a 21-day lockdown from midnight onwards to control the spread of COVID-19. The lockdown was further extended, and India was under a nationwide lockdown till $3^{\text {rd }}$ May, though some rules had been eased in areas which are not COVID hotspots. ${ }^{[3]}$ Lockdown 3.0 - the nationwide lockdown which was set to end on $3^{\text {rd }}$ May 2020, has been extended by two more weeks till May $17^{\text {th }}$ 2020. There are three zones designated to districts, namely,

This is an open access journal, and articles are distributed under the terms of the Creative Commons Attribution-NonCommercial-ShareAlike 4.0 License, which allows others to remix, tweak, and build upon the work non-commercially, as long as appropriate credit is given and the new creations are licensed under the identical terms.

For reprints contact: WKHLRPMedknow_reprints@wolterskluwer.com

Cite this article as: Ahuja G, Verma M, Patkar D. Financial impact of COVID-19 on radiology practice in India. Indian J Radiol Imaging 2021;31:S31-7.

Received: 29-Apr-2020

Accepted: 05-Jul-2020

Revised: 04-May-2020 Published: 23-Jan-2021 
red, orange, and green based on the number of cases. This classification determines the restrictions placed on the movement of people, business activities, and supply/sale of goods.

Measures taken to control the pandemic like social distancing and lockdown are going to bring with them larger challenges on livelihood in general and the economy in particular, which has already been slow in the previous year.

The government is taking all efforts to help soften the blow of the economic impact by providing relief packages like providing a moratorium on EMIs of all outstanding loans for a specified period and allocating 15,000 crores toward reinforcing healthcare infrastructure. ${ }^{[4]}$

We will be discussing the economic effects of the pandemic on healthcare sector in general with focus on radiology perspective. We would like to provide insights into the financial issues faced by radiology service providers during these difficult times and what measures can be taken to sustain these.

\section{Statistics in INDIA as of $6^{\text {th }}$ May 2020}

\begin{tabular}{lccc}
\hline Active cases & Cured/discharged & Deaths & Migrated \\
\hline 33514 & 14182 & 1694 & 1
\end{tabular}

Source: Ministry of Health and family welfare

As of $6^{\text {th }}$ May 2020, the total number of active cases in India was 33514 . The number is rising every minute. ${ }^{[5]} \mathrm{An}$ attempt to curtail this is the government's primary motive right now to safeguard life first.

While announcing the lockdown, PM Modi had said "jaan hai to jahan hai" thus keeping the focus on flattening the curve and saving lives. Post phase-1 of lockdown, during a video conference with chief ministers of 13 states, PM Modi underlined the motto of the government "jaan bhi jahaan bhi" which emphasized on the need to resume the economic activities while containing the spread of the disease. This is to be done in phases with reasonable safeguards. The Prime Minister also talked about strengthening healthcare infrastructure and reaching out to patients through telemedicine. ${ }^{[6]}$

\section{Financial Environment of Pre-COVID-19}

Projections for financial growth (before the pandemic crisis started) stated that India's GDP was growing at $6.5 \% .{ }^{[7]}$ Asian Development Bank (ADB) had cut India's growth forecast to $5.1 \%$ from previous $6.5 \%$ for $2019-20$ and India's growth estimate for FY2020-21 to 6.5\% from 7.2\% in December 2019. The economy had already slowed down due to credit crunch and weakening domestic demand. ${ }^{[8]}$ Moody's Investors
Service had lowered its 2019 GDP growth forecast for India to $5.6 \%$ and expected economic growth to pick up in 2020 and 2021 to $6.6 \%$ and $6.7 \%$, respectively [Figure 1]. ${ }^{[9]}$

These projections have drastically changed since the COVID pandemic hit our economy.

\section{Current Financial Environment}

Financial Impact in India: Containment measures taken to reduce transmission of disease will lead to a short-term decline in GDP for most countries including India [Figure 2].

We all know that initial containment measures like partial/ complete lockdowns across the world to contain the spread of COVID will have catastrophic effects on the economy. With some initial estimates, the percentage drop will vary from $20 \%-30 \%$. New GDP growth estimates for India range from 1.9 to $3.5^{[10]}$ (Source: Reports from Moody's Investor Service, EIU, SEP Global Ratings, CRISIL Ltd, IMF, Press articles).

According to experts, this pandemic might bring the $3^{\text {rd }}$ greatest economic, financial, and social shock of the $21^{\text {st }}$ century, post the 9/11 and subprime crises, which led to a global financial meltdown. ${ }^{[11]}$ The economic impact of the latter two on India was due to ripple effects but this pandemic will have direct and cumulative effects both.

Up to $53 \%$ of businesses will be affected by COVID-19 (FICCI survey). ${ }^{[12]}$ According to former Reserve Bank of India chief Raghuram Rajan, the coronavirus pandemic in India may just be the "greatest emergency since Independence." [13]

With economic activity coming to a standstill and spike in unemployment and looming uncertainty over the future, all industries that thrive on discretionary spending like tourism, hospitality, fashion \& luxury goods, automobile, housing, oil and gas, etc., will take a severe hit. Various businesses such as hotels and airlines are cutting salaries

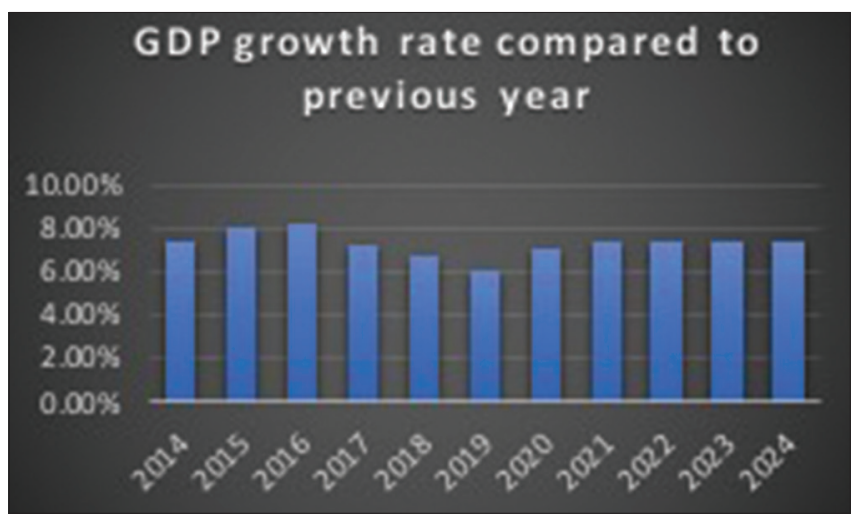

Figure 1: INDIA-GDP growth rate from 2014 to 2018 and projected growth rate from 2019 to 2024. Source: Available from: https://www. statista.com/statistics/263617/gross-domestic-product 
and laying off employees. Confederation of Indian Industries (CII) President of the tourism vertical estimated a potential loss of approximately 2 crore livelihoods across the tourism industry in India. Several young start-ups have been impacted as funding has fallen. On 23 March 2020, stock markets in India posted worst losses in history. ${ }^{[14]}$ SENSEX fell 4000 points (13.15\%) and NSE NIFTY fell 1150 points $(12.98 \%) .{ }^{[15]}$ Stock markets have taken a beating; there has been some temporary stability after Central banks worldwide have tried to infuse liquidity and Governments have tried to inspire confidence by announcing relief packages. But the volatility is here to stay for some time, especially until the real extent of the pandemic pans out.

Every economic crisis brings with it positive effects for some. Certain industries like media, online education portals, consumer staples, food/drug retails, pharmaceuticals, personal protection equipment (PPE) manufacturers/ distributors, and telecommunication are seeing an upside during this economic crisis.

\section{Financial Impact on the Healthcare Sector}

The bar chart shows that on an average, for every 1000 patients in India, we have less than 1 bed available ${ }^{[16]}$ (This number varies in India from state to state ranging from 2.4 beds to 0.3 beds per 1000 patients). In comparison to Italy, Spain, and USA, where community spread has rendered these developed economies' healthcare systems incapable to handle this catastrophe, our infrastructure is much weaker to handle a similar situation. This amplifies the fact that the best option left with us is to maintain a complete lockdown to prevent overburdening our available scarce resources and infrastructure [Figures 3 and 4].

We spend approximately 3.6\% of our GDP for healthcare, out of which the government spending is a meagre $0.9 \% .{ }^{[17]}$ If we compare ourselves with developed countries like USA where government spending is approximately $14.3 \%$ or even with our peer countries, for example, Brazil where it is $4 \%$, our spending is too less.

Also, since out of $3.6 \%, 2.4 \%$ is spent by private households (out of pocket), the impact on the healthcare industry in India will be strongly governed by spending power of the population.

\section{Impact on Hospitals}

Hospitals everywhere are facing a twin burden: 1) Drop in footfall, leading to decreasing revenue and 2) increase in expenditure on manpower and consumables to ensure preparedness.

\section{Drop in footfall}

Hospitals are cancelling elective surgeries and limiting OPD services so as to conserve vital resources which may

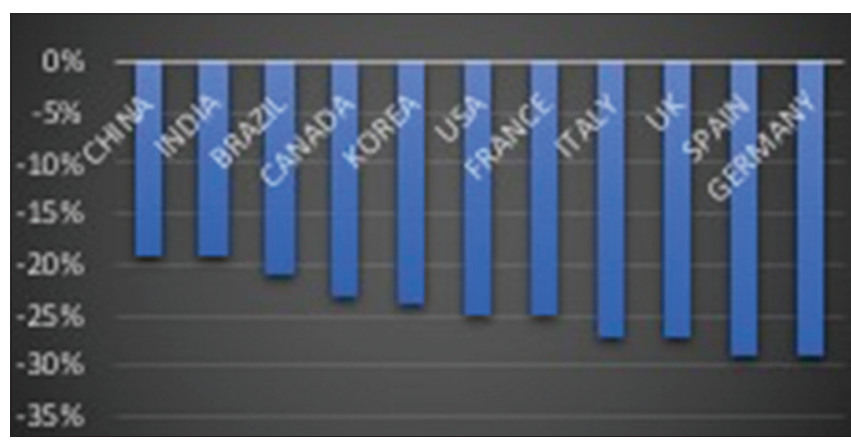

Figure 2: Initial impact of containment measures. Selected countries $\%$ decline in GDP at constant prices. Source: OECD Annual National accounts, OECD trade in value-added database, statistics Korea Brazilian Institute of Geography and Statistics and OECD calculations

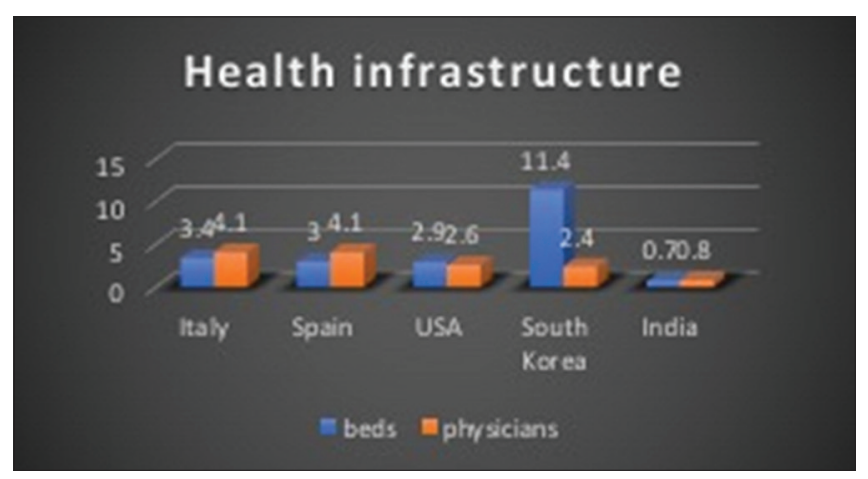

Figure 3: Health infrastructure in different countries. Source: World Bank, WHO, country data varies from 2011 to 2017

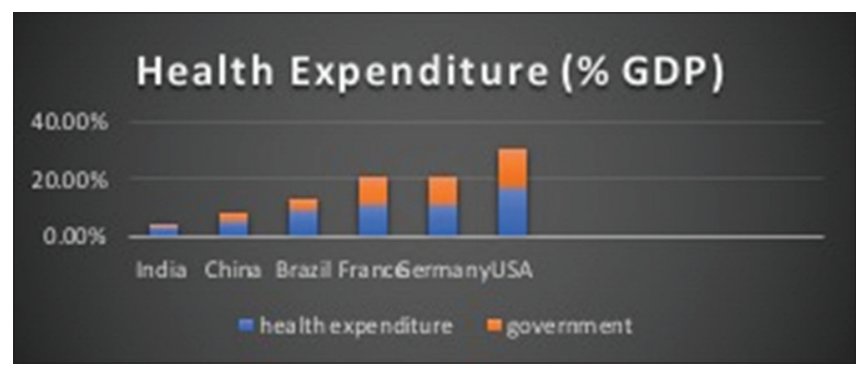

Figure 4: Health expenditure. Source: OECD 2020, health expenditure and financing: health expenditure indicators

be needed to provide care to those who ultimately may need it the most. Elective procedures, routine nonemergent investigations (laboratory and imaging), and international patients are the main source of profits for bigger hospitals. Their significant reduction has resulted in major revenue loss. Fixed cost of expenditure for a private hospital is quite significant, further contributing to losses. Reduction in revenue will have a serious long-term financial impact.

A recent study by consultancy firm E\&Y and industry chamber FICCI found that the private hospitals and laboratories have seen occupancy levels fall to $40 \%$ by late-March vis-a-vis precoronavirus occupancy levels of $65 \%$ to $70 \% \cdot{ }^{[18]}$ FICCI-EY study estimates the operating losses of private healthcare providers to be about Rs 4500 crore for 
a month and Rs 13,400 crore for a quarter if revenues are at $50 \%$ (occupancy of $35 \%$ ). This pandemic has resulted in a $70 \%$ drop in footfalls and test volumes in private hospitals. ${ }^{[19]}$ Loss of international patients and cancelling elective surgeries have caused a $50 \%-70 \%$ drop in revenue in the month of March [Figure 5]. ${ }^{[19]}$

\section{Increasing expenditure}

Hospitals are investing in additional manpower training besides bearing additional costs incurred for maintaining staff safety (like PPE), supplies for disinfection, and sanitization, investment in equipment like ventilators, remodeling rooms for accommodating positive patients, and arranging ambulances for patient transfers. This is to ensure preparedness for a potential surge of patients. Increasing costs and decreasing revenues act as a threat to their financial viability, quickly depleting cash reserves which may disrupt ongoing hospital operations.

Since most corporate hospital chains are over leveraged, these difficult times will make it challenging for them to sustain.

\section{Impact on Radiology Practice}

The COVID crisis has crippled Radiology services all over the country. Though hospitals and centers have found ways to deal with it in the form of Teleradiology, the effects are still distressing.

There will be both short-term and long-term effects of this pandemic on radiology practice.

Factors responsible for short-term effects of economic losses:

1. Rescheduling/cancelling elective radiology procedures

2. Cancelling outpatient services thus reducing referrals

3. Lockdown and social distancing restricting patient movement

4. Financial insecurity in general population causing deferment of nonurgent investigations

5. Reduced hospital admissions

6. Private hospitals volunteering to accommodate COVID positive patients causing a reduced influx of general patient population due to avoidance of risk of transmission.

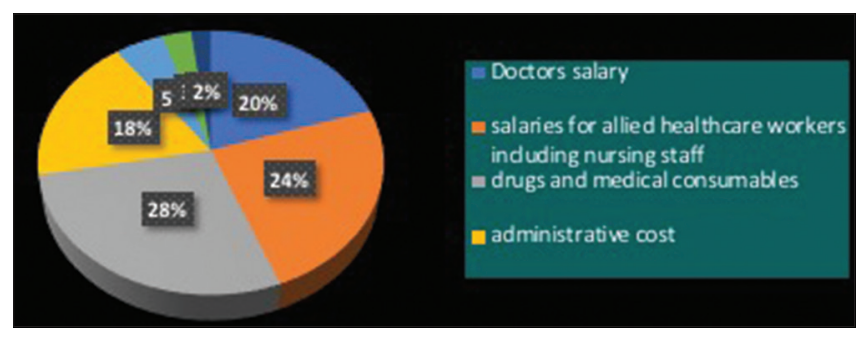

Figure 5: Hospital setup fixed cost. Source: Association of healthcare providers in India (AHPI) report, The New Indian Express ${ }^{[20]}$
7. Admissions and outpatient services of hospitals being sealed or being declared containment zones.

Types of radiology setups affected:

a. Radiology departments in hospitals

b. Stand-alone Radiology/Diagnostics centers.

Radiology departments in hospitals

Radiology investigations form an integral part of patient management. Reduced footfall in hospitals due to curtailment of outpatient services has also affected the imaging volumes in radiology departments. In an attempt to reduce transmission, radiology departments across hospitals have rescheduled/cancelled all elective diagnostic scans and procedures. Almost all outpatient investigations are cancelled except for the ones with medical or surgical emergency/semiemergency indications. Emergency radiological investigations form only a small proportion of investigations in a diagnostic setup. All these factors have cumulatively hampered revenue.

All radiology investigations, namely, magnetic resonance imaging (MRI), computed tomography (CT scan), ultrasound (USG), and X-ray have taken a hit. MRI scan volumes have been severely affected. Since only emergency/ semiemergency investigations are being performed, there has been a decline in business by almost $60 \%-70 \%$. Since $X$-rays and $\mathrm{CT}$ scans are indicated in the management of COVID as well as patients in Intensive Care Units, for surveillance and monitoring, numbers are still being maintained, though not as much as the Pre-COVID era. The Ultrasound department also has seen decreasing numbers as pregnant women are especially being cautioned to reduce the number of investigations and doctor visits. Only scans which are necessary in pregnancy and would alter management are being advised like NT scan (11-13.6 weeks) and Anomaly scans (18-20 weeks).

Screening mammography and DEXA scans also have been rescheduled, further contributing to a decrease in revenue.

Imaging has a limited role in COVID-19 patients. Imaging is indicated where it will impact the management or is clinically indicated and to rule out other causes for a sudden worsening of disease like pulmonary thromboembolism, pulmonary edema as also in case of urgent/unrelated causes like stroke. ${ }^{[21]}$ Imaging in these patients has added to the volumes but the overall numbers are still low.

\section{Stand-alone radiology/diagnostics centers}

Lockdown and social distancing have hampered outpatient department services at clinics, nursing homes, dispensaries, and smaller hospitals, thus reducing referrals for imaging investigations. Patient movement also has been curtailed due to the above reasons. Diagnostic labs have seen $80 \%$ fall in patient visits and revenue. Revenue of stand-alone 
diagnostic setups has significantly gone down by at least $60 \%$ to $70 \%{ }^{[18]}$ Centers with a daily imaging load of $15-20$ are doing less than 5-6 scans per day. Diagnostic MRI centers are severely affected as nonurgent scans are being deferred by patients as well as physicians and surgeons. Ultrasound scans have also gone down. However regardless of the imaging modality, the overheads (operative costs) required to maintain an imaging diagnostic center like EMIs, salaries, electricity, machine maintenance costs, etc., still need to be taken care of. This is definitely eating into the savings of owners. Besides these expenses, costs have increased as these setups also need to make provisions for all safety precautions for the staff including PPEs as also cleaning equipment and solutions, disinfection materials to prevent transmission to the vulnerable patient population. The financial stress worsened by COVID-19 lockdown has forced several standalone and small nursing homes in tier II and III cities to shut down. Many others are at high risk of closing down soon since their cash flows have dried up, due to steep decline in patient footfalls, and liquidity crisis making it difficult for even sustaining their staff salaries [Figure 6] $\cdot^{[18]}$

\section{Radiologists}

Financial future of radiologists is at stake secondary to layoffs, salary cuts, and losses. The risk of inability to pay EMIs looms large. The government has provided some relief in the form of relief packages under which, they have instructed banks to give borrowers a grace period of 3 months for payment of EMIs.

To ensure their safety, radiologists in diagnostic radiology have been given an option of working from home with the help of remote access to picture archiving and communication system (PACS) provided by hospitals, wherever feasible. However interventional radiologists cannot use this option, they must be prepared to continue their service taking utmost precautions while handling patients, especially emergency and important elective procedures.

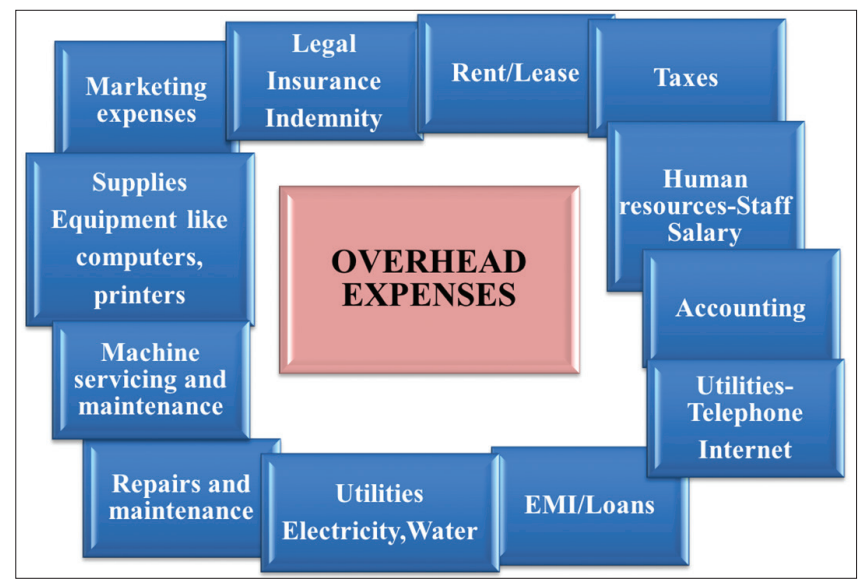

Figure 6: Overhead expenses of a diagnostic center
Senior radiologists may delay retirement due to losses in savings. Economic crisis has put a load on human psychology as well.

\section{Radiology technicians}

Layoffs and salary cuts are going to severely affect technicians as well. Not to forget the psychological burden of going back to families after working in an environment which can put them at risk.

\section{Radiology trainees}

Social distancing measures have put a hindrance on the traditional way of trainee-teacher workstation teaching. The junior residents during their initial rotations are the ones seriously affected academically, though teleconferencing, webinars, and remote readout sessions with screen sharing may help in these situations.

Trainees with debts and limited earnings and savings are the ones seriously affected. Concerns about security and existing and future job offers add on to their problems in the current scenario. Fellowships and distance learning opportunities are also put on hold by residents which puts a looming uncertainty on their careers and financial future.

\section{Radiology conferences}

Significant losses have been incurred, due to cancellations of preplanned conferences due to government restrictions of lockdown and social distancing, not just by organizers but also delegates. Digital and virtual meeting platforms are potential alternatives.

\section{Long-Term Effects of this Pandemic on Radiology Practice}

Due to financial stress, patients will defer nonurgent investigations. Since outpatient elective imaging investigations are not covered under insurance and due to reduced out-of-pocket expenditure capacity of patients, there will be a decrease in imaging volumes and in revenues.

Digital health services like telemedicine/teleradiology, artificial intelligence, and deep learning technologies will see acceleration and wide acceptance in the long run.

The ease of remote reporting might even have permanent effects on how the radiology practice functions in the post-COVID era. However, this will have an impact on training and education of new radiologists in the making.

Innovation and technology in radiology like portable CT scanners will see a positive impact. Technology can help alleviate some of the strain which doctors might face in the post-COVID era. Investigations like screening mammograms are currently being deferred. Doctors will surely need help managing the backlog after the virus. Tools 
which use AI to prioritize suspicious cases that need timely attention to help focus and support early cancer detection, can prove to be very helpful.

How can radiology departments and centers sustain during this crisis?

Digital health is turning out to be a promising solution currently. ${ }^{[22]}$ Teleradiology has proved to be a key enabler during these difficult times. Hospitals have provided home workstations with remote access to radiologists wherever feasible. Teleradiology has made it possible for radiologists to view and report scans from their homes and provide immediate guidance in patient care and management. This makes teleradiology an ideal solution in this situation as it not only protects radiologists from the risk of exposure but also gives them a chance to provide their much-needed expert guidance.

Training sessions, lectures, webinars, and other educational activities can be provided online to ensure continuous learning is not hampered.

Artificial intelligence and deep learning are promising technologies which can help radiologists to triage patients based on the severity of findings and identify suspicious COVID patients which might have been missed in routine testing. These will garner much importance in the long run.

New technologies and innovations like portable CT scanners will add a tremendous value in the current situation.

Radiology services everywhere should prepare themselves for a surge in patients after the smoke clears. People who stop seeking treatment for long-term issues, routine problems, or minor ailments will return the moment they feel safe to do so.

Rather than treating this disaster as a one-time difficulty, it is imperative to acknowledge the long-term changes created by this pandemic and work proactively to develop future-facing strategies.

What expectations would private hospitals/diagnostic setups have from governments to help them tide over this crisis?

The FICCI-E\&Y report, which looked at the median performance of 74 hospital groups and 17 diagnostic chains suggests that the central government should take urgent measures to assist the private sector players through liquidity infusion, tax reliefs, and other waivers to tide over the crisis. ${ }^{[23]}$

Other ways in which the government could provide some relief would be to offer a rebate on the current commercial rates of power being paid by hospitals, diagnostics centers, and other healthcare service providers to ensure sustenance of business, subsidies in salaries for healthcare staff, comprehensive medical and life insurance benefits for healthcare workers, and ensuring continuous availability of personal protection equipment.

On March 26, the government approved the insurance scheme for health workers (doctors, sanitation staff, Asha workers, paramedics, and nurses) fighting the novel coronavirus. A Rs 50 lakh insurance cover per person for frontline healthcare workers involved in managing the Coronavirus (COVID-19) outbreak was announced by the minister of Finance Nirmala Sitharaman. ${ }^{[4]}$

A long-pending decision for the safety of healthcare workers was finally taken by the government. An ordinance has been passed by the government on April 22, 2020 for safety of healthcare workers, making acts of violence against doctors and frontline personnel a cognizable and nonbailable offence punishable with imprisonment up to 7 years. ${ }^{[25]}$

\section{Conclusion}

The final impact of this pandemic is still uncertain and depends on the type of economic recovery. The longer the recession lasts, the greater will be the economic harm. The government is trying to gradually restart the economic shutdown by relaxing lockdowns in specific zones and allocating funds toward strengthening health infrastructure. Eventually, this pandemic will end, and life will have a "New Normal." Medical aid that is being deferred today will be sought out later. Cancelled visits, investigations, and surgeries are going to be rescheduled for later and eventually, business losses could also be recovered. No one could have predicted this catastrophe before it happened, but the equivalent does not hold true for the post-COVID business landscape. When the numbers fall and doctors have more of the supplies and knowledge they need, life will return to something resembling normal. Hospitals and radiologists need to make plans before the storm clears to ensure their survival in the post-COVID era.

Funds for expenses of hospitals and radiology centers come from three primary sources: operating cash flows, equity, and debt. The management of all three sources must be well coordinated to fund and sustain all ongoing and future activities. Ultimately, it will be a combination of aid/benefits provided by the government and individual managerial decisions by radiologists that will determine what our practice environments look like in the post-COVID era.

Though reduced revenues and profits are causing a major stress on hospitals and radiology centers, there will be ways to weather this storm and we must not lose hope. Doctors are the soldiers the world will remember once this war is over. Our current priorities for COVID-19 preparedness should be to focus on early detection, limiting exposure, safety precautions, training, and maintenance of operations and 
staffing. Patience, cool minds, new administrative strategies, individual and cumulative discipline, a heightened sense of solidarity, and a shared sense of purpose are all we need currently to overcome these unprecedented and challenging circumstances.

\section{Financial support and sponsorship}

Nil.

\section{Conflicts of interest}

There are no conflicts of interest.

\section{References}

1. WHO (world health organization). Available from: https://www. who.int/. [Last accessed on 2020 Apr 24].

2. Radiology Department Preparedness for COVID-19: Radiology Scientific Expert Panel Mahmud Mossa-Basha, Carolyn C. Meltzer, Danny C Kim, Michael J Tuite, K. Pallav Kolli, and Bien Soo Tan, Radiology. Available from: https://pubs.rsna.org/doi/10.1148/ radiol. 2020200988. [Last accessed on 2020 Apr 24].

3. Available from: https://qz.com/india/1842004/continued-lockdownis-indias-best-bet-against-coronavirus/. [Last accessed on $2020 \mathrm{Apr}$ 23].

4. RBI joins coronavirus fight with big-bang rate move, EMIs put on hold The Economic Times. 27 March 2020. Retrieved 22 April 2020.

5. Ministry of Health and Family Welfare. Available from: https:// www.mohfw.gov.in/. [Last accessed on 2020 Apr 22].

6. Available from: https://www.businesstoday.in/current/ economy-politics/coronavirus-update-jaan-bhijahaan-bhi-pm-m odi-pitches-new-motto-to-contain-pandemic/story/400761.html. [Last accessed on 2020 Apr 22].

7. CIMF, World Economic Outlook, October 2019. Available from: https://www.imf.org/external/datamapper/NGDP_RPCH@WEO/ OEMDC/ADVEC/WEOWORLD/VEN/AFG. [Last accessed on 2020 Apr 22].

8. Available from: https://www.indiatoday.in/business/story/e-con clave-corona-series-top-editor-martin-wolf-shares-how-india-c an-shield-companies-amid-pandemic-1670161-2020-04-23. [Last accessed on 2020 Apr 23].

9. Moody's cuts India's GDP growth forecast to $5.6 \%$ for 2019 , Economic times, Dec 13 2019, Retrieved April 23 2020. Available from: https://economictimes.indiatimes.com/news/economy/indicators/ moodys-cuts-indias-gdp-growth-forecast-to-5-6-for-2019/ articleshow/72520706.cms?from=mdr. [Last accessed on $2020 \mathrm{Apr}$ 23].
10. Reports from Moody's Investor Service, IMF, EIU, S\&P Global Ratings, CRISIL Ltd. [Last accessed on 2020 Apr 24].

11. Coronavirus (COVID-19): Joint actions to win the war-OECD.org.

12. Mukherji B. Coronavirus impact: Indian industry seeks relief measures to aid economy. Livemint 2020. Retrieved 23 March 2020.

13. Ghosh D. Greatest Emergency since Independence: Raghuram Rajan on COVID-19. NDTV 2020. Retrieved 22 ${ }^{\text {nd }}$ April 2020.

14. Stock markets post worst losses in history; Sensex crashes 3,935 points amid coronavirus lockdown. The Indian Express. 23 March 2020. Retrieved 22 April 2020.

15. Sensex crashes 4,000 points: What's behind market meltdown. The Economic Times. 23 March 2020. Retrieved 23 March 2020.

16. Available from: World bank, https://data.worldbank.org/. [Last accessed on 2020 Apr 22].

17. OECD. Health spending (indicator). 2020. doi: 10.1787/8643de7e-en. [Last accessed on 2020 Apr 22].

18. COVID-19 pandemic leaves the private healthcare sector in financial distress: FICCI-EY study. Available from: https://www. thehindubusinessline.com/publish $d 17^{\text {th }}$ April. Retrieved April 23, 2020.

19. Covid-19 outbreak: A near-death experience for private hospitals, too-Declining footfalls, rising consumables and staff costs have put private hospitals' survival at stake. By Teena Thacker Last Updated: Apr 20, 2020, 09.59 PM IST, Retrieved-April 23, 2020.

20. Private hospitals spend 50 per cent of operational costs on salaries of medical staff, including doctors: June 16 2018. Report, AHPI. 2018.

21. Mossa-Basha M, Meltzer CC, Kim DC, Tuite MJ, Kolli KP, Tan BS. Radiology department preparedness for COVID-19: Radiology scientific expert panel. Radiology 2020:200988. doi: 10.1148/radiol. 2020200988.

22. Ting DSW, Carin L, Dzau V, Wong TY. Digital technology and COVID-19. Nat Med 2020;26:459-61.

23. Private hospitals in trouble: Footfall crashes due to coronavirus fear; occupancy level falls 40\% Business Today, Apr 16, 2020, Retrieved April 232020.

24. Government approves insurance scheme for health workers fighting COVID-19, ET Online. Available from: https://economictimes. indiatimes.com/news/economy/policy/government-approv es-insurance-scheme-for-health-workers-fighting-covid-19/ articleshow/74875243.cms?from=mdr. [Last accessed on $2020 \mathrm{Apr}$ 15].

25. Up to 7 years' jail for attack on healtworkers, Times of India, April 23 2020. Retrieved April 23 2020. Available from: http://timesofindia.indiatimes.com/articleshow/75309166. cms?utm_source $=$ contentofinterest\&utm_medium=text\&utm campaign $=$ cppst. [Last accessed on 2020 Apr 24]. 